\title{
Instructional Leadership Practice and Professional Learning Community in the Southern Zone of Malaysia
}

\author{
Roslizam Hassan*, Jamilah Ahmad, Yusof Boon \\ School of Education, Universiti Teknologi Malaysia (UTM), Malaysia
}

Received August 23, 2019; Revised November 24, 2019; Accepted December 3, 2019

Copyright@2019 by authors, all rights reserved. Authors agree that this article remains permanently open access under the terms of the Creative Commons Attribution License 4.0 International License

\begin{abstract}
This article investigates the level of instructional leadership (IL) of principals and professional learning community (PLC) among teachers in the southern zone of Malaysia which is Johor, Negeri Sembilan and Melaka to analyze the relationship between these two elements. This research also studies which of the IL dimensions can best measure the practice of PLC. This research applied survey research design using IL and PLC questionnaire (KIProQ). The alpha Cronbach value for the pilot study of KIProQ for IL is .962 while for PLC is .930. This study involved 390 teachers that had been chosen using proportional cluster random sampling method. The statistical analysis in this study uses the software IBM SPSS Statistic version 22. The research result found that the principals in the southern zone of Malaysia have practiced IL at medium high level with all three dimensions recorded a mean score value of between 3.796 and 3.965. It was also found that the PLC practice among teachers was at medium high level with the mean score values of all five dimensions being between 3.685 and 4.082. This study also found that the relationship between IL and PLC is statistically significant and positive $(\mathrm{r}=.658, \mathrm{p}<.01)$ and the relationship is at medium level. A beta correlation coefficient value analysis had shown that two of the three dimensions in IL were identified as the best predictor for the practice of PLC which is the dimension promoting school climate $(\beta=.518, t=7.164$ and $p=.000)$ and the dimension managing instructional programme $(\beta=.188$, $\mathrm{t}=2.595$ and $\mathrm{p}=.010$ ). In summary, the practice of IL and PLC has been implemented by the principals and teachers in the southern zone of Malaysia in driving the school towards achieving the stated vision and mission. IL practice is also proven to influence the effectiveness of the PLC practice among teachers and consequently fulfill the effort to make PLC as a culture that must be instilled in schools.
\end{abstract}

Keywords Instructional Leadership, Professional Learning Community, Southern Zone of Malaysia

\section{Introduction}

The correlation between school leadership and profesional learning community (PLC) practiced among teachers emerged when many researchers had agreed that the school leaders play a major role in creating and maintaining PLC in schools (Gartner, 2010; Geijsel, Sleegers, Stoel, \& Krüger, 2009; Stoll, Bolam, McMahon, Wallace, \& Thomas, 2006). Literature had proven that the role of leaders in creating and supporting the sustainability of PLC is vital. Louis and Kruse (1994) had successfully identified two ways on how leadership can influence or affect the PLC culture. The first one is by putting leadership at a visible condition and always ready to share the leadership and the second one is by encouraging or promoting supports in the classroom. The importance of leaders in encouraging PLC culture is also noted in a brief statement by Youngs and King (2002) which stated that the success of leaders in supporting PLC culture depends on the extent of similarity between the roles and responsibilities they practice and the responsibilities that they had defined. Therefore, this clearly shows that what has been practiced by the school leaders in their work environment that has a direct effect on the effectiveness of PLC.

The relationship between leadership and PLC is also proven when Clear (2005) had particularly defined PLC as a collegial group consisting of school leaders and teachers who always work together and learn together with the aim to improve the students' academic achievement. The researcher had also highlighted that teachers who felt encouraged by the school leaders in practicing PLC will be more committed and efficient in their lifelong learning process and their practice in the classroom, compared to those who did not get any support from the school leaders. This shows that PLC is a powerful tool in developing teachers' professionalism.

Furthermore, according to Scoggins (2008) leadership style practiced by school leaders can have a positive or negative impact on PLC development in a school. He also found that the improvement of teacher leadership capabilities 
caused by the leadership style of their school leaders has also affected the development of PLC in the school. As a result, this study has succeeded in adding literary materials related to educational leadership by stating that a school leader's leadership style is closely related to PLC culture. The findings of this study have also provided its own specialized basic knowledge to improve the quality of PLC implementation in schools. Furthermore, many past researchers such as Blankstein (2004); Huffman and Hipp (2003); and Reeves (2006) suggested that school leaders play a big and important role in helping their schools to cultivate PLC.

McLaughlin and Talbert (2001) also pointed out that it was difficult for them to predict the success of PLC implementation in schools if they did not get support from school leaders. This support comes in how they manage school resources, support or impede social interactions, respond to the various educational policies that are available, and most importantly, bring in as many resources available to schools to fulfill various demands in PLC cultivation. Besides, school leaders also help create a learning culture by emphasizing the importance of teacher learning as well as critical dialogue and reflection as they influence the social and physical climate of the school (Griffith, 1999).

School leaders also provide the core elements needed to maintain PLC sustainability through a number of ways such as their words and actions, how they build their teacher schedules and their ability to distribute teacher workloads so that teachers' duties and responsibilities can be shared fairly and equally. While the social interaction of school leaders can be seen to facilitate in developing trust, collaboration and dissemination of knowledge and expertise among teachers. School leaders can also help teachers to face various demands from the new educational policies or the many and rapid changes that are seen to be extremely disturbing the continuity of the school's improvement process (DeMatthews, 2014).

Based on the discussion above, it can be concluded that leadership plays an important role in ensuring the sustainability of PLC culture in a school. Support in either humanity or resources is crucial to ensure that learning culture among teachers can be continued so that all knowledge and expertise can be shared and spread widely. Ultimately, this will improve the teacher's quality and students' academic achievement.

\section{Research Objectives}

The objective of this research is to identify the level of practice for the principals' IL and PLC in three states of the Southern Zone of Malaysia which are Johor, Negeri Sembilan and Melaka and the relationship between the two practices. To be more precise, this study has four objectives to be fulfilled to reach the aims of the study which are as follow: i. To identify the level of principals' IL in the southern zone of Malaysia.

ii. To identify the level of PLC among teachers in the southern zone of Malaysia.

iii. To analyze the relationship between IL and PLC.

iv. To determine the dimension of IL that can be the best predictor for the PLC practice.

\section{Research Design}

This research applies quantitative method using survey to study the principals' practice level of IL and the teachers' practice level of PLC in the Southern Zone of Malaysia. The quantitative design is chosen because of its ability to analyze numerical data in a research in which the data has been collected and analyzed to clarify and forecast a phenomenon (Chua, 2006; Gay, Mills, \& Airasian, 2012; Muijs, 2011).

Surveys through questionnaire had been popular in various fields, especially in science social researches (Chua, 2006) and education (McMillan, 2013). According to Gay et al., (2012), survey research is suitable for researches that include an evaluation on perceptions, attitudes, trust, practice, interest or characteristics of a group of respondents. This survey method is chosen for its ability to give measurable explanation through numeric for the PLC variable, it is more economically efficient and also accurate in presenting information regarding the research population (Muijs, 2011).

\subsection{Research Sample and Population}

The research population focused on teachers who serve at national schools in Johor, Negeri Sembilan and Melaka. Based on the draft obtained by the Department of State Education for the three states on the $31^{\text {st }}$ of December 2016, the total number of teachers is 30,830 people. To determine the sample size for this study, several basic considerations had been taken. According to Cohen et al. (2013), a research which applies random sampling technique requires a big sample size so that the sample can illustrate the represented population accurately. Besides, the research design also affects the sample size. For quantitative researches, the sample size required is huge especially if inferential statistics are implemented in the research (Cohen et al., 2013).

Based on the Sample Size Table by Krejcie and Morgan, for a population of 30,830 people, the number of sample needed is only 379 people (Krejcie \& Morgan, 1970; Sekaran, 2003). However, in this research, the researcher added the sample size up to 390 people. This value is obtained after the original value has been rounded off. Adding the number of samples is encouraged and suggested by Babbie (2014), Cohen et al. (2013), Creswell (2014) and Slavin (2007) in which they believe that the bigger the sample size is the better it avoids errors in sampling, increases reliability and makes up for the probability of the questionnaire not being returned. 


\subsection{Research Instrument}

This study uses a questionnaire of IL and PLC (KIProQ) which comprises 75 items to study the principals' practice level of IL and the teachers' practice level of PLC in Johor, Negeri Sembilan and Melaka. The alpha Cronbach value for the pilot study of KIProQ is 0.962 for IL and 0.930 for PLC. KIProQ was constructed by the researcher based on the dimensions used in building the two best questionnaires in the field of IL and PLC which are "Principal Instructional Management Rating Scale” (PIMRS) by Hallinger (1990) and "School Professional Staff as Learning Communities Questionnaire” (SPSLCQ) by Hord (1997a). The researcher only applies the dimensions in the questionnaire and all items in this study's instrument are constructed by the researcher himself to suit Malaysian education system.

\subsection{Descriptive Statistical Analysis}

In this research, descriptive analysis based on mean score value is used to identify the level of practice of IL and PLC. To measure the level of mean score, Table of Mean Score Interpretation constructed by Nunnally and Berstein (1994) is used in this study. The Table is as shown in Table 1.

Table 1. Table of Mean Score Interpretation (Nunnally \& Berstein, 1994)

\begin{tabular}{cc}
\hline Mean Scale & Level \\
\hline $4.01-5.00$ & High \\
\hline $3.01-4.00$ & Medium High \\
\hline $2.01-3.00$ & Medium Low \\
\hline $1.00-2.00$ & Low \\
\hline
\end{tabular}

\subsection{Inferential Statistical Analysis}

Inferential statistics explain the relationship between variables and the characteristics of samples chosen from a research population (Chua, 2006b). According to Sekaran (2003), the data analysis method for inferential statistics is used to get an inference from statistics of a sample to the whole population. In this study, inferential statistics which are Pearson-correlation and multiple regression were used to achieve the third and fourth objectives.

\subsubsection{Pearson-Correlation Test}

The third objective is to analyze the relationship between two variables which are IL and PLC. To achieve this objective, Pearson-Correlation Test (Pearson Product-moment) with numerical scales being used (Chua, 2006b; McMillan, 2013). According to Babbie (2012) and Shaughnessy, Zechmeister, and Zechmeister (2012), Pearson-Correlation Test is suitable to be used for two variables with interval scale. The strength of a correlation is represented by correlation coefficient (r), a value that shows the strength of a relationship between two variables (independent and dependent). Chua (2006b) stated that the correlation coefficient (r) is in between +1.00 to -1.00 as shown in Table 2.

Table 2. Correlation Coefficient and Correlation Strength (Chua, 2006b)

\begin{tabular}{cc}
\hline Correlation Coefficient Size (r) & Correlation Strength \\
\hline .91 to 1.00 or -.91 to -1.00 & Very Strong \\
\hline .71 to .90 or -.71 to -.90 & Strong \\
\hline .51 to .70 or -.51 to -.70 & Medium \\
\hline .31 to .50 or -.31 to -.50 & Weak \\
\hline .01 to .30 or -.01 to -.30 & Very Weak \\
\hline .00 & No Correlation \\
\hline
\end{tabular}

\subsubsection{Multiple Regression Test}

Multiple regression test is used to identify changes in two or more factors (independent variables) that contribute to changes in a dependent variable (Chua, 2006b). Howitt and Cramer (2011) stated that multiple regression tests are the statistical tests used to find the best predictors (independent variables) by showing the value of relationships and contributions $\left(\mathrm{r}^{2}\right)$ between the studied variables simultaneously. Through multiple regression analysis, the effectiveness of independent variables (predictors) will be shown when it is simultaneously tested with the assumption that they have equal interest in dependent variables (Field, 2013). According to Chua (2006b), there are three types of procedures in conducting multiple regression: first, backward settlement procedure (full mode), second, forward settlement procedure and third, stepwise settlement procedure (by level or step by step).

For the purpose of this study, the third procedure, which is stepwise (stepwise) settlement procedure was used in achieving the fourth objective of the study. This procedure has several advantages over the first two procedures. According to Diekhoff (1992), this procedure is more economical than two other procedures because through this procedure only a significant predictor variable will be included in the regression. The second advantage is that this procedure avoids the occurrence of multicollinearity problems that occurred due to the strong correlation between the predictor variables. This strong correlation will cause the regression analysis to run poorly (Diekhoff, 1992). This problem can be solved by not including the problematic variable in the regression.

To interpret the findings from multiple regression, the value of $\mathrm{r}^{2}$ (also known as coefficient of determination) will be used to measure the percentage of changes in the dependent variable (criterion) which was caused by the changes in predictor variables (independent) (Bryman \& Cramer, 2001; Creswell, 2012; Fraenkel, Wallen, \& Hyun, 2014; Miller, 2005). The $\mathrm{r}^{2}$ value is between 0 and 1 which can also be converted to a percentage of 0 to 100 percent. For example, if the $\mathrm{r}^{2}$ reading for multiple regression analysis test between the first predictor variables (defining goals - the first dimensions of IL) with the dependent variable (criterion) is .695 , this means that the first predictor variable can 
influence up to 69.5 percent variance towards the dependent variable (criterion), which is the PLC practice in school.

\section{Research Findings}

\subsection{Principals' IL Practice Level in the Southern Zone of Malaysia}

After analyzing each item in the IL functions, a full analysis based on 3 dimensions and 10 functions can be summarized as shown in Table 3. This analysis is explained by using the values of mean and standard deviation as well as the interpretation of the practice level. Referring to the table, it was found that the level of IL practice was at medium high $(\mathrm{M}=3.8850, \mathrm{SP}=.59626)$. In terms of the comparison between the dimensions, it was found that the practice of defining the school goal showed a mean $(\mathrm{M}=3.9646$, SP $=.6976)$ which was higher than the overall mean value $(\mathrm{M}=$ 3.8550), while the dimension of organizing instructional program $(\mathrm{M}=3.8043, \mathrm{SP}=6105)$ and promoting school climate $(\mathrm{M}=3.7961, \mathrm{SP}=.6005)$ showed lower mean.

An analysis had also been performed for each function to determine the level of practice of those functions that represent the three dimensions of IL. The dimensions of defining the school goals consisting of two functions indicate that the principals practice the task of framing the school goals $(\mathrm{M}=3.9026, \mathrm{SP}=.7275)$ and communicating school goals $(\mathrm{M}=4.0267, \mathrm{SP}=.7330)$ at moderate high and high levels. For the dimension of managing instructional programs which have three functions, the principal is able to carry out all the functions at medium high level which are supervising and making instructional evaluations $(\mathrm{M}=$ 3.8621, $\mathrm{SP}=.6554)$, coordinating the curriculum $(\mathrm{M}=$ 3.9041, SP $=.6588$ ) and monitoring students' development $(\mathrm{M}=3.6467, \mathrm{SP}=.6665)$.

The third dimension is to encourage the school climate and only one function is practiced by the principals at high level which is to encourage professional development $(\mathrm{M}=4.0451$, $\mathrm{SP}=$.6356) among teachers. While the other four functions show that the principals practice functions such as protecting instructional period $(\mathrm{M}=3.7282$, $\mathrm{SP}=.6447)$, always seen $(\mathrm{M}=3.6892, \mathrm{SP}=.7107)$, providing incentives for teachers $(\mathrm{M}=3.6328$, SP $=.7656)$ and incentives for students' learning $(\mathrm{M}=3.8851, \mathrm{SP}=.7146)$ at medium high level.

Overall, the principals in the Southern Zone of Malaysia show medium high level of IL practice based on the three dimensions and the 10 functions found in the leadership. The dimension with the highest implementation stage is defining school goals, followed by the management of instructional programmes and promoting school climate. Therefore, it can be concluded that the principals in the Southern Zone of Malaysia have practiced IL in leading the teachers to enhance academic excellence and student development.

Table 3. Analysis for the Principals’ IL Practice Level

\begin{tabular}{cccc}
\hline Dimension and function & Mean (M) & Standard Deviation (SD) & Practice Level \\
\hline Defining school goals & 3.9646 & .6976 & Medium High \\
\hline Framing school goals & 3.9026 & .7275 & Medium High \\
\hline Communicating school goals & 4.0267 & .7330 & High \\
\hline Managing instructional programmes & 3.8043 & .6105 & Medium High \\
\hline $\begin{array}{c}\text { Supervising and evaluating } \\
\text { instructional }\end{array}$ & 3.8621 & .6554 & Medium High \\
\hline Coordinating the curriculum & 3.9041 & .6588 & Medium High \\
\hline Monitoring students' development & 3.6467 & .6665 & Medium High \\
\hline $\begin{array}{c}\text { Promoting school climate } \\
\text { Protecting instructional period }\end{array}$ & 3.7961 & .6005 & Medium High \\
\hline Always seen & 3.7282 & .6447 & Medium High \\
\hline Providing incentives for teachers & 3.6892 & .7107 & Medium High \\
\hline $\begin{array}{c}\text { Encouraging professional } \\
\text { development }\end{array}$ & 3.6328 & .7656 & High \\
\hline $\begin{array}{c}\text { Providing incentives for } \\
\text { students' learning }\end{array}$ & 4.0451 & .6356 & Medium High \\
\hline \begin{tabular}{c} 
Overall mean \\
\hline
\end{tabular} & 3.8851 & .7146 & Medium High \\
\hline
\end{tabular}




\subsection{Teachers' Practice Level of PLC in the Southern Zone of Malaysia}

The overall analysis of PLC implementation among teachers in the Southern Zone of Malaysia is based on the five dimensions of PLC as shown in Table 4. This analysis is explained using mean and standard deviation as well as the interpretation of the practice level. Based on the table, it is clear that PLC practice among teachers in the Southern Zone of Malaysia is at medium high level $(\mathrm{M}=3.8456$, SP $=.47534)$. The dimension of sharing the vision and missions is the only dimension that is practiced at high level $(\mathrm{M}=$ $4.0821, \mathrm{SP}=.5444$ ) and it exceeded the overall mean value. Meanwhile, the other four dimensions are below the overall mean value and have a medium level of practice. The dimensions are collective learning and learning application $(\mathrm{M}=3.8564, \mathrm{SP}=.5237)$, followed by dimension of leadership sharing and supportive leadership $(M=3.8323$, $\mathrm{SP}=.6301)$, and the dimension of organization support $(\mathrm{M}=$ 3.7723 , SP $=.6284)$. Whereas the dimension with the lowest mean score is the sharing of personal practices $(\mathrm{M}=3.6851$, $\mathrm{SP}=.5625$ ).

Overall, teachers in the Southern Zone of Malaysia have practiced PLC at medium high to high levels and the dimension of sharing vision and mission is the highest performing dimensions. Meanwhile, other dimensions such as leadership sharing and supportive leadership, collective learning and learning application, sharing of personal practices and organization support are still practiced but at medium high levels. Hence, it can be concluded that the teachers in the Southern Zone of Malaysia have embraced PLC practices in their daily work with the aim of improving self-quality from various aspects, particularly in teaching, to contribute to the quality of learning and academic achievement of students.

\subsection{Analyzing the Relationship between IL and PLC}

To study the relationship between the principals' IL practice and the teachers' implementation of PLC in the Southern Zone of Malaysia, a Pearson correlation test (Pearson Product-moment) was conducted as the data for both variables are ordinal. This test is also used to test the first hypothesis which is:

Ho1: There is no significant relationship between IL and the PLC.

The correlation strength between the relationships of both variables is based on correlation coefficient and correlation strength (Refer Table 2). The result of Pearson correlation analysis is shown in Table 5.

Table 4. Analysis of PLC Practice Level

\begin{tabular}{cccc}
\hline Dimensions & Mean (M) & Standard Deviation (SD) & Practice Level \\
\hline Sharing of vision and mission & 4.0821 & .5444 & High \\
\hline Leadership sharing and supportive leadership & 3.8323 & .6301 & Medium High \\
\hline Collective learning and learning application & 3.8564 & .5237 & Medium High \\
\hline Sharing of personal practices & 3.6851 & .5625 & Medium High \\
\hline Organization support & 3.7723 & .6284 & Medium High \\
\hline Overall mean & $\mathbf{3 . 8 4 5 6}$ & $\mathbf{. 4 7 5 3}$ & Medium high \\
\hline
\end{tabular}

Table 5. Correlation of IL and PLC

\begin{tabular}{cccc}
\hline Dimension & \multicolumn{3}{c}{ PLC } \\
\cline { 2 - 4 } & $\mathbf{r}$ & $\mathbf{r}^{2}$ & Sig** \\
\hline Defining school goals & .549 & .301 & .000 \\
\hline Managing instructional programmes & .633 & .401 & .000 \\
\hline Promoting school climate & .679 & .461 & .000 \\
\hline IL & .658 & .433 & .000 \\
\hline Note: ${ }^{* *}$ correlation is significant at $\mathrm{p}<.01$ & & & \\
\hline
\end{tabular}


Based on the results of the analysis, it is found that the relationship between IL and PLC is statistically significant and positive $(\mathrm{r}=.658, \mathrm{p}<.01)$. However, the relationship exists at medium level. The value of the variance $\left(r^{2}=.433\right)$ indicates that 43.3 percent of the overall change in the implementation of PLC practice among teachers is due to the principal's IL factor. Meanwhile 56.7 percent of further changes in PLC implementation may be due to other factors that were not studied in this research.

Based on these findings, the Ho1 hypothesis is rejected as there is a significant relationship, but at medium level between the principals' practice of IL and the teachers' practice of the PLC in the Southern Zone of Malaysia. This study has also analyzed the relationship between the three dimensions of IL and the PLC practice. The findings show that there are statistically significant and positive relationships between the three dimensions and the PLC practice. All dimensions that represent IL show a medium relationship, in which they are the dimensions of promoting the school climate $(r=.679, \mathrm{p}<.01)$, followed by the dimension of managing instructional programmes $(r=.633$, $\mathrm{p}<.01)$ and dimension of defining school goals $(\mathrm{r}=.549$, $\mathrm{p}$ $<.01)$.

In conclusion, based on the perception of teachers in the Southern Zone of Malaysia, it is found that there is a statistically and positively significant relationship between IL and PLC, and their correlation strength is moderate. This finding clearly demonstrates that the principals' IL is able to influence the implementation of PLC among teachers. The implication is that the higher the level of IL practice of the principals is, the higher the PLC practice is among the teachers in the Southern Zone of Malaysia which are Johor, Negeri Sembilan and Melaka.

\subsection{Identifying the IL dimension that can be the Best Predictor for the Practice of PLC}

Multiple regression analysis was used to identify what is the dimension of IL (independent variables) that can be the best predictor of the implementation of PLC (dependent variable) among teachers in the Southern Zone of Malaysia. In addition, multiple regression analysis was also conducted to test the second hypothesis of the study which is:

Ho2: No dimension of IL is the best predictor of the professional learning community practice.
Hypothesis Ho2 is explained in detail below:

Ho2a: There is no dimension of defining school goals as the best predictor of the PLC practice.

Ho2b: There is no dimension of managing instructional programmes as the best predictor of the PLC practice.

Ho2c: There is no dimension of promoting the school climate as the best predictor of the PLC practice.

Table 6 shows that among the three dimensions of IL, only two dimensions have correlation and contribute significantly (47\%) statistically $(\mathrm{p}<.05)$ towards the teachers' PLC practice in the Southern Zone of Malaysia.

The two dimensions are promoting school climate (the third dimension) and managing instructional programmes (the second dimension). However, based on Ho2a, Ho2b, and Ho2c that have been constructed, the results of this study have rejected the assumptions of the researcher in Ho2b, and Ho2c which stated that managing instructional programmes and promoting the school climate are not the best predictor for PLC practice. This means that only Ho2a is accepted, where there is no dimension of defining school goals as the best predictor in the practice of PLC.

The best and highest predictor of teachers' PLC practice in the Southern Zone of Malaysia is the dimension of promoting school climate $(\beta=.518, t=7.164$ and $p=.000)$. Significant t-test at $\mathrm{p}<.05$ and $\mathrm{R}$ square value $\left(\mathrm{R}^{2}=.461\right)$ shows that the dimension of promoting school climate has 46.1 percent of contribution in PLC implementation. This situation explains that when the IL score of principals for the dimension promoted the school climate increase in one unit, then the level of PLC practice among teachers increased by .518 units. This finding demonstrates that the dimension of promoting the school climate from the principals' IL is the best predictor which contributed 46.1 percent to the practice of the PLC among teachers in the Southern Zone of Malaysia.

The second predictor which had contributed as much as .9 percent to PLC practice is the dimension of managing instructional programmes $(\beta=.188, \mathrm{t}=2.595$ and $\mathrm{p}=.010)$. The t-test result was also significant at $\mathrm{p}<.05$ and the value of $\mathrm{R}$ squared $\left(\mathrm{R}^{2}=.470\right)$. This means that when the principals' IL score for the dimension of managing instructional programmes increases by one unit, the teacher's PLC practice also increases by .188 units. 
Table 6. Analysis Multiple Regression (Stepwise): IL Dimension Contribution to Changes in the Practice of PLC

\begin{tabular}{|c|c|c|c|c|c|c|}
\hline Dimension of IL & B & Beta $(\beta)$ & t value & Sig. t & $\mathbf{R}^{2}$ & Contribution (\%) \\
\hline Promoting school climate & .410 & .518 & 7.164 & .000 & .461 & 46.1 \\
\hline Managing instructional programme & .146 & .188 & 2.595 & .010 & .470 & .9 \\
\hline Constant & 1.733 & & 14.964 & .000 & & \\
\hline $\mathrm{R}$ & & .686 & & & & \\
\hline $\mathrm{R}^{2}$ & & .471 & & & & \\
\hline Adjusted R ${ }^{2}$ & & .470 & & & & \\
\hline Standard Error & & .347 & & & & \\
\hline
\end{tabular}

Table 7. Analysis of Multiple Regression (Stepwise): Variance Analysis

\begin{tabular}{cccccc}
\hline Source & Squared Total & Degree of Freedom & Squared Mean & F Value & Significant Level (p) \\
\hline Regression & 41.353 & 2 & 20.676 & 171.933 & .000 \\
\hline \multicolumn{1}{c}{} & & & & \\
\hline Residual & 46.540 & 387 & & \\
\hline & & & & \\
\hline Total & 87.893 & 389 & & \\
\hline Note: * significant at $\mathrm{p}<.05$ & & & & \\
\hline
\end{tabular}

The F-test result in Table 7 shows that there is a relationship between the two dimensions in the independent variable (IL) and the teachers' PLC practice $(\mathrm{F}(2,387)=$ 171.933) at the significant level $p<.05$. The result of the multiple regression analysis carried out giving the $\mathrm{R}$ square value $\left(R^{2}=.470\right)$ showed a change in the combination of two dimensions of IL which are promoting school climate and managing instructional programmes where they contributed 47 percent to changes in teachers' PLC practice in the Southern Zone of Malaysia. This means that there is a 53 percent change in the teachers' PLC practice that is unpredictable due to other variables (other factors) that are not studied in this study.

Generally, the overall contribution of two independent variables (promoting school climate and managing instructional programmes) which are significant towards the teachers' PLC practice in the Southern Zone of Malaysia can be formed through the regression equation as shown in the following:

$$
\mathrm{Y}=.518 \mathrm{X} 1+\cdot .188 \mathrm{X} 2
$$

Where;

$\mathrm{Y}=$ Teachers’ PLC practice

$\mathrm{X} 1$ = Promoting school climate

X2 = Managing instructional programmes

Based on the above regression equation, it can be concluded that the dimensions of promoting school climate and managing instructional programs have significant correlations, give contributions and are the predictors for teachers' PLC practice in the Southern Zone of Malaysia. It is found that the key predictor of the teachers' PLC practice is promoting the school climate, followed by managing instructional programmes. This means that only Ho2a is accepted because there is no dimension of defining school goals as the best predictor of the practice of PLC.

\section{Conclusions}

In general, the principals' practice of IL and the teachers' practice of PLC in the Southern Zone of Malaysia is at medium high level. The findings also show that there is a statistically and positively significant relationship between the IL and PLC, and this proves that the principals' IL practice can influence their teacher's practice of PLC. In order to identify the best predictor in encouraging the practice of PLC, the findings show that only two dimensions of IL are the best predictors of the PLC practice, which are promoting school climate and managing instructional programmes. In conclusion, the efforts of the principals and teachers in carrying out their respective duties should be acknowledged and recognized as they had done their best to cultivate quality work culture in their environment, solely to enhance students' academic and subsequently to achieve the dreams of ministries to produce educated individuals that would bring harmony to the country. 


\section{REFERENCES}

[1] Babbie, E. (2012). The practice of social research (12th ed.). Belmont, CA: Cengage Learning.

[2] Babbie, E. (2014). The basic of social research (6th. ed.). USA: Wadsworth Cengage Learning.

[3] Blankstein, A. M. (2004). Failure is not an option: Six principles that guide student achievement in high performing schools. Thousands Oaks, CA: Corwin Press \& Hope Foundation.

[4] Bryman, A., \& Cramer, D. (2001). Quantitative data analysis with SPSS release 10 for windows: A guide for social scientists (1st ed.). Philadelphia, USA: Routledge Taylor \& Francis Group. http://doi.org/10.4324/9780203471548

[5] Chua, Y. P. (2006). Asas statistik penyelidikan: Kaedah dan statistik penyelidikan (Buku 2). Kuala Lumpur: McGraw-Hill (Malaysia) Sdn. Bhd.

[6] Clear, E. A. Le. (2005). Relationships among leadership styles, school culture, and student achievement. University of Florida. Retrieved fromhttp://onlinelibrary.wiley.com/doi/10 .1002/cbdv.200490137/abstract\%5Cnhttp://etd.fcla.edu/UF/ UFE0013022/leclear_e.pdf

[7] Cohen, L., Manion, L., \& Morrison, K. (2013). Research methods in education (7th ed.). New York and London: Routledge Taylor \& Francis Group. http://doi.org/10.1080/19415257.2011.643130

[8] Creswell, J. W. (2012). Educational research: Planning, conducting, and evaluating quantitative and qualitative research. Educational Research (Vol. 4). http://doi.org/10.1017/CBO9781107415324.004

[9] Creswell, J. W. (2014). Research design: Qualitative, quantitative, and mixed methods approaches (4th ed.). London: SAGE Publication. http://doi.org/10.4135/9781849208956

[10] DeMatthews, D. (2014). Principal and teacher collaboration: An exploration of distributed leadership in professional learning communities. International Journal of Educational Leadership and Management, 2(2), 176-206. http://doi.org/10.4471/ijelm.2014.16

[11] Diekhoff, G. M. (1992). Statistics for the social and behavioral sciences: Univariate, bivariate and multivariate. Dubuque: William C Brown Publishers.

[12] Field, A. (2013). Discovering statistics using IBM SPSS statistics (4th ed.). London: SAGE Publication.

[13] Fraenkel, J. R., Wallen, N. E., \& Hyun, H. H. (2014). How to design and evaluate research in education (9th ed.). New York: McGraw-Hill Education.

[14] Gartner, S. (2010). The importance of professional learning communities to improve classroom instruction. Martin Luther College.

[15] Gay, L. R., Mills, G. E., \& Airasian, P. (2012). Educational research: Competencies for analysis and applications (10th ed.). New York: Pearson.
[16] Geijsel, F. P., Sleegers, P. J. C., Stoel, R. D., \& Krüger, M. L. (2009). The effect of teacher psychological and school organizational and leadership factors on teachers' professional learning in Dutch schools. The Elementary School Journal, 109(4), 406-427. http://doi.org/10.1086/593940

[17] Griffith, J. (1999). The school leadership/school climate relation: Identification of school configurations associated with change in principals. Educational Administration Quarterly, 35(2), 267-291. http://doi.org/10.1177/00131619 921968545

[18] Hallinger, P. (1990). Principal instructional management rating scale: Teacher form. Sarasota, FL: Leading Development Associates.

[19] Hord, S. M. (1997). Professional learning communities: Communities of continuous inquiry and improvement. Austin, Texas: Southwest Educational Development Laboratory. http://doi.org/10.1177/1365480210376487

[20] Howitt, D., \& Cramer, D. (2011). Introduction to research methods in psychology (3rd ed.). Edinburgh Gate: Pearson.

[21] Huffman, J. B., \& Hipp, K. K. (2003). Reculturing schools as professional learning communities. Lanham, MA: Scarecrow Education.

[22] James H. McMillan. (2013). SAGE Handbook of research on classroom assessment. Sage Publications. Thousands Oaks, CA: SAGE Publication.

[23] Krejcie, R. V, \& Morgan, D. (1970). Determining sample size for research activities. Educational and Psychological Measurement, 30, 607-610.

[24] Louis, K. S., \& Kruse, S. D. (1994). Professionalism and community: Perspectives on reforming urban school. Newbury Park, CA.

[25] McLaughlin, M. W., \& Talbert, J. E. (2001). Professional communities and the work of high school teaching (1st. Ed.). Chicago, IL: University of Chicago Press.

[26] Miller, J. E. (2005). The Chicago guide to writing about multivariate analysis. Chicago and London: The University of Chicago Press. http://doi.org/10.1198/tas.2006.s43

[27] Muijs, D. (2011). Doing quantitative research in education with SPSS (2nd. ed.). London: SAGE Publication.

[28] Nunnally, J. C., \& Berstein, I. H. (1994). Psychometric theory (3rd ed.). New York: McGraw-Hill.

[29] Reeves, D. B. (2006). The learning leader: How to focus school improvement for better results. Alexandria, USA: Association for Supervision and Curriculum Development.

[30] Scoggins, K. T. (2008). The impact of leadership capacity and style on professional learning communities in schools. University of North Texas.

[31] Sekaran, U. (2003). Research methods for business: A skill-building approach (5th ed.). Chichester, United Kingdom: John Wiley \& Sons Ltd. http://doi.org/10.1017/CBO9781107415324.004

[32] Shaughnessy, J. J., Zechmeister, E. B., \& Zechmeister, J. S. (2012). Research methods in psychology (9th ed.). McGraw-Hill. 
[33] Slavin, R. E. (2007). Educational research in an age of accountability. Virginia, USA: Pearson.

[34] Stoll, L., Bolam, R., McMahon, A., Wallace, M., \& Thomas, S. (2006). Professional learning communities: A review of the literature. Journal of Educational Change, 7, 221-258. http://doi.org/10.1007/s10833-006-0001-8

[35] Youngs, P., \& King, M. B. (2002). Principal leadership for professional development to build school capacity. Educational Administration Quarterly, 38(5), 643-670. http://doi.org/10.1177/0013161X02239642 